\section{Human Infection with Adult Toxocara cati}

\section{British Medical Fournal, 1969, 3, 454-455}

Infection of human beings with Toxocara cati or $T$. canis, the common roundworm of cats and dogs, respectively, commonly occurs in young children with a history of pica or close contact with domestic animals, for infection arises from ingestion of ova passed in the animals' faeces. Larvae from within these ingested ova pass into the circulation of the human host and migrate to distant organs, causing inflammatory exudates and eosinophilic granulomata.

It is rare for the larvae to complete their cycle of development in the human host, and thus infection with the adult form of toxocara is seldom seen. Only two cases of human infection with the adult $T$. canis have been reported (Leiper, 19.07 ; Bisseru et al., 1966), and only 19 with adult T. cati (reviewed by Mendheim et al., 1952), many of which were of doubtful validity. The following report of infection with the adult $T$. cati is of interest, as positive identification was made of the worms vomited by the patient but no evidence could be found of larval migration through the tissues. It is postulated that a different mode of transmission occurred from that which normally leads to visceral or ocular toxocariasis.

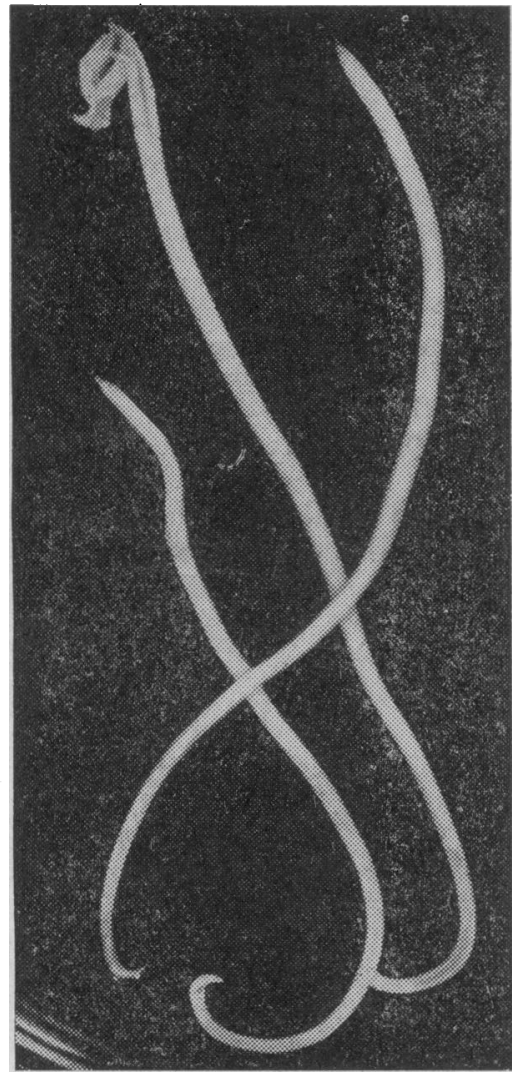

FIG. 1.-Three female adult worms of Toxocara species. (Actual size.)

\section{CAse Report}

A 14-month-old boy, born of English parents, and who had never been abroad, was seen by the family's doctor because he had vomited three worms. His mother did not see the worms being vomited, as she was not in the room at that particular moment, but no other person or animal was present during her absence and the vomitus was of the same consistency and colour as that which the child had brought up previously on the same day. The mother was certain that the child had vomited the specimen. The child was in good health, though he sometimes ate dirt. One episode of vomiting had occurred two months previously. His father, a farm manager, kept a cat and a dog, but on later examination of the faeces of these animals no toxocara ova were found.

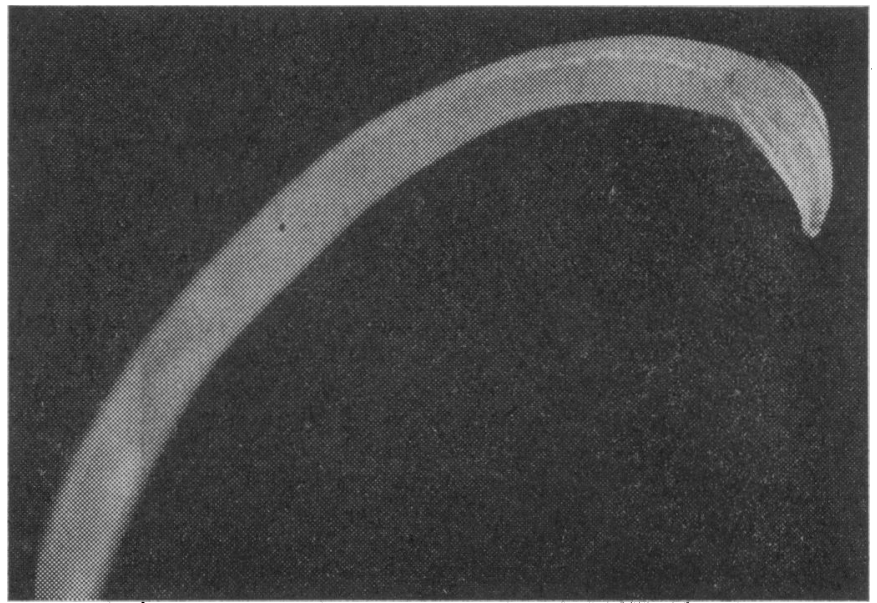

FIG. 2.-Cephalic end of one worm, showing bulging alae characteristic of Toxocara cati. (X4.)

The child was well when seen, and there was no history of cough, fever, fits, or visual disturbance. Clinical examination failed to show any abnormalities. Because the worms had been provisionally identified as Toxocara species the boy was admitted to hospital. Haemoglobin was found to be $11.6 \mathrm{~g} . / 100 \mathrm{ml}$; the white cell count was $9,000 / \mathrm{cu}$. mm., with a normal differential including

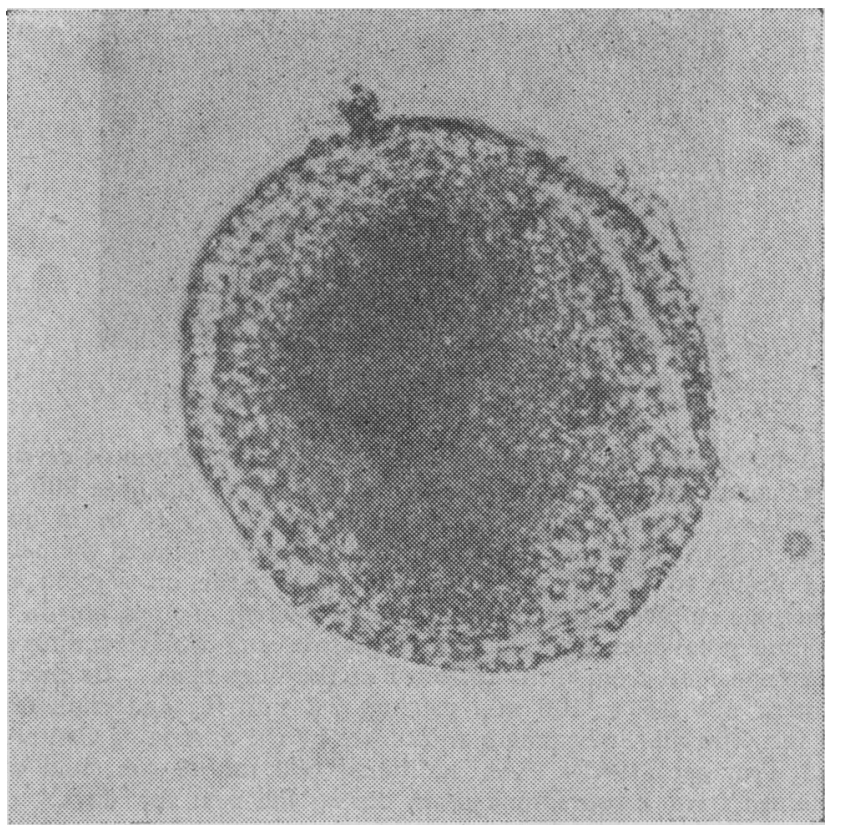

Fig. 3.-Unembryonated egg of Toxocara species dissected from one of the worms. The pitting of the egg-shell is characteristic. $(x$ about 750 .)

only $1.5 \%$ eosinophil cells (absolute count 135 cells/cu. mm.); the erythrocyte sedimentation rate was $9 \mathrm{~mm}$./hour (Westergren); and the plasma protein estimation and electrophoretic pattern were within normal limits. Repeat white cell counts and differentials over several days showed little change. Two stool examinations and a centrifugal concentration of a total three-day stool collection showed no helminthic ova or protozoan cysts. The chest $x$-ray picture was normal. The toxocaral skin test was negative on all occasions on which it was carried out. The toxocaral fluorescent antibody test was negative both on the serum taken at the time when first seen and on specimens taken on subsequent occasions. 
The child remained well and was given Pripsen (piperazine phosphate and standardized senna B.P.) 3 g., but no further helminths were recovered.

The parasites were confirmed as being adult Toxocara cati by Professor Sprent and Dr. E. G. Warren. Dr. Warren wrote: “All three worms are females, and the presence of a simple ventriculus, large cervical alae and eggs with a pitted surface are conclusive of membership of the genus Toxocara." (Figs. 1-3.)

\section{COMMENT}

Strong evidence was present that the patient had vomited the three nematodes, and these were later positively identified as $T$. cati. Investigations shortly after this, however, failed to show any haematological or serological evidence of toxocaral infection. The toxocaral skin test has been shown to be reliable and valuable for the diagnosis of toxocariasis (Woodruff and Thacker, 1964; Wiseman and Woodruff, 1967), and the toxocaral fluorescent antibody test is a reliable and specific indicator of active infection (Wiseman and Woodruff, to be reported). Ingestion of toxocara eggs, with the consequent migration of larvae through the tisues, is known to give rise tis a pronounced eosinophilia and leucocytosis in experimentally infected animals (Wiseman and Woodruff, 1967), in human volunteers (Smith and Beaver, 1955), as well as in naturally infected patients (Beaver et al., 1952). The absence of eosinothilia in this patient, combined with the negative skin test and the negative fluorescent antibody test, suggested, therefore, that migration of larvae through the circulation and organs had not occurred.

The life-cycle of $T$. cati is complex, but, basically, ingestion of embryonated ova by accidental hosts can lead to the development of second-stage larvae which migrate through the tissues; this may occur in many species of animals - in man the symptoms of visceral toxocariasis ("visceral larva migrans") result.

The ingestion of second-stage larvae instead of eggs by cats (Sprent, 1956) or dogs (Sprent and English, 1958) (as, for example, by feeding on the carcasses of toxocara-infected mice) leads to the development of adult worms in the digestive tract. Similarly it was found that the feeding of $T$. canis-infected mice livers to a second batch of mice led to the development of some larvae in the intestine, though none were found in the tissues (Wiseman, unpublished data). Infection of humans with the adult worm might oocur in the same way ; an investigation has shown that $T$. canis larvae were capable of surviving and remaining highly motile after incubation in human gastric juice (Wiseman and Woodruff, unpublished data).

If infection of human beings with the adult worm occurs by ingestion of larvae rather than eggs, then it appears probable that the larvae develop direct in the intestine to maturity without any circulatory or tissue phase of migration. Therefore no haematological or serological evidence of toxocaral infection could be expected. The case reported above would seem to substantiate this hypothesis.

Further support for this postulate appears to come from the first human case of $T$. cati infection recorded in man. "The subject was a woman who habitually ate the earth from the graves of priests, and as a result of her unusual eating habits frequently vomited beetles, suggesting that human infection may possibly result from the accidental ingestion of beetles, cockroaches, or other intermediate hosts" (Sprent, 1956). It is suggested that a similar event occurred in the case described here, and that the unusual eating habits required for the development of the adult worm: in humans may account for its apparent rarity.

We wish to thank Professor J. F. A. Sprent and Dr. E. G. Warren, of the department of parasitology, University of Queensland, Australia, and Mr. F. R. N. Pester, of the department of parasitology, London School of Hygiene and Tropical Medicine, for their help in the identification of the parasite; Dr. M. N. Hughes, Public Health Laboratory Service, Winchester, for contacting the London School of Hygiene and Tropical Medicine; Mr. C. J. Webb, visual aids department of the London School of Hygiene and Tropical Medicine, for the photography ; and Professor A. W. Woodruff for guidance in the preparation of the paper.

\section{R. A. WISEMAN, PH.D., D.T.M.\&H., D.OBST.R.C.O.G., London School of Hygiene and Tropical Medicine, and Medical Unit, Hospital for Tropical Diseases, London.}

T. W. I. LOVEL, M.A., B.M., M.R.C.P., General Practitioner, Andover, Hants.

\section{REFERENCES}

Beaver, P. C., Snyder, C. H., Carrera, G. M., Dent, J. H., and Lafferty, J. W. (1952): - Pediatrics, 9, 7.

Bisseru, B., Woodruff, A. W., and Hutchinson, R. I. (1966). British Medical fournal, $1,1583$.

Leiper, R. T. (1907). British Medical fournal, 1, 1296.

Mendheim, H., Scheid, G., and Schmidt, J. (1952). Zeitschrift für Tropenmedizin und Parasitologie, 3, 368.

Smith, M. H. D., and Beaver, P. C. (1955). Pediatric Clinics of North America, 2, 163.

Sprent, J. F. A. (1956). Parasitology, 46, 54.

Sprent, J. F. A., and English, P. B. (1958). Australian Veterinary fournal, 34, 161 .

Wiseman, R. A., and Woodruff, A. W. (1967). Transactions of the Royal Society of Tropical Medicine and Hygiene, 61, 827.

Woodruff, A. W., and Thacker, C. K. (1964). British Medical fournal, 1, 1001 . 